https://doi.org/10.15407/dopovidi2021.03.048

УДК 541.35.3:546.26

В.В. Потоцька ${ }^{1}$, https://orcid.org/0000-0001-7269-9592

O.I. Гічан ${ }^{2}$, https://orcid.org/0000-0002-5812-9451

А.О. Омельчук ${ }^{1}$, https://orcid.org/0000-0002-8799-2115

${ }^{1}$ Інститут загальної та неорганічної хімії ім. В.І. Вернадського НАН України, Київ

${ }^{2}$ Інститут хімії поверхні ім. О.О. Чуйка НАН України, Київ

E-mail: omelchuk@ionc.kiev.ua, gichan@meta.ua

\title{
Закономірності сумісного розряду іонів. Теорія електрохімічного синтезу
}

Представлено членом-кореспондентом НАН України А.О. Омельчуком

Показано закономірності сумісного розряду двох іонів для різних умов поляризащії електрода: концентраційної, змішаної (конщентраційно-кінетичної) та кінетичного контролю у випадку сповільненого розряду обох іонів. Показано, як незалежні процеси розряду іонів стають залежними при сумісному розряді. Отримано рівняння поляризаційної кривої для електрохімічного синтезу у випадку конщентраційної поляризацї електрода (розглянуто сумісний розряд двох іонів та подальша сповільнена гетерогенна хімічна реакиія синтезу). При иьому зсув перенапруги залежить від величини заряду іонів, що розряджаються, густини струмів розряду та густини струму обміну хімічної реакціӥ синтезу, різниці величин стандартних потенціалів.

Ключові слова: сумісний розряд, поляризачійна крива, електрохімічний синтез, сплави.

В основі електрохімічного синтезу лежить можливість сумісного або послідовного виділення з електроліту компонентів синтезованої сполуки. Відповідно до існуючих законів електродних процесів [1-6] необхідною умовою для одночасного розряду декількох типів іонів $є$ один і той самий потенціал відновлення. Електроосадження металів є найбільш простим, контрольованим і ефективним шляхом отримання сплавів [7]. Сумісний розряд іонів металів супроводжується реакцією виділення водню на поверхні катоду. Критичним параметром при осадженні металів на катоді є рН. Врахування реакції виділення водню значно ускладнює математичні розрахунки. Ми будемо розглядати виділення металів із розплавів.

Розглянемо різні випадки сумісного розряду двох іонів металу

$$
\begin{aligned}
& M_{1}^{z_{1}+}+z_{1} e \rightleftarrows M_{1}, \\
& M_{2}^{z_{2}+}+z_{2} e \rightleftarrows M_{2} .
\end{aligned}
$$

Ци ту в ан н я: Потоцька В.В., Гічан О.І., Омельчук А.О. Закономірності сумісного розряду іонів. Теорія електрохімічного синтезу. Допов. Нащ. акад. наук Укр. 2021. № 3. С. 48-54. https://doi.org/10.15407/ dopovidi2021.03.048 
Puc. 1. Граф, на якому зображено процеси, що протікають в приелектродному шарі. Константи швидкості: $k_{1}, k_{2}-$ прямої та зворотної хімічних реакцій, $k_{f 1}, k_{f 2}-$ прямих, $k_{-f 1}, k_{-f 2}-$ зворотних електрохімічних реакцій.

Реакція синтезу, яка відбувається із речовин, що утворюються на поверхні катода

$$
M_{1}+M_{2} \rightleftarrows M_{1} M_{2} \text {. }
$$

Весь процес електрохімічного синтезу можна описати графом, наведеним на рис.1. Із рисунка видно, яким чином подальша гетерогенна хімічна реакція впливає на потенціал електрода.

\section{Сумісний розряд в умовах концентраційної поляризації.}

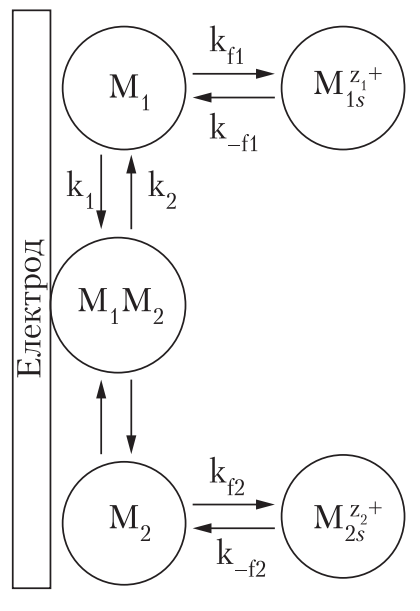
Нехай в електроліті присутні два сорти іонів $M_{1}^{z_{1}}$ з концентрацією $C_{1}$ та іони $M_{2}^{z_{2}} 3$ концентрацією $C_{2}$, що відновлюються на поверхні катода в заданій області потенціалів. В умовах концентраційної поляризації для оборотних електрохімічних реакцій потенціал електрода описується рівнянням Нернста:

$$
\begin{aligned}
& E=E_{1}^{0}+\frac{R T}{z_{1} F} \ln \frac{C_{1}^{s}}{C_{1}^{0}}, \\
& E=E_{2}^{0}+\frac{R T}{z_{2} F} \ln \frac{C_{2}^{s}}{C_{2}^{0}},
\end{aligned}
$$

де $E$ - потенціал електрода; $C_{1}^{0}, C_{2}^{0}-$ об’ємні концентрації; $C_{1}^{s}, C_{2}^{s}-$ поверхневі концентрації; $z_{1}, z_{2}$ - заряд іонів першого та другого сорту; $E_{1}^{0}, E_{2}^{0}-$ стандартні потенціали; $R$ - газова постійна; $F-$ постійна Фарадея; $T$-абсолютна температура.

Із рівнянь (4) та (5) маємо

$$
\frac{C_{1}^{s}}{C_{1}^{0}}=\left(\frac{C_{2}^{s}}{C_{2}^{0}}\right) z_{1} / z_{2} e^{\left(E_{2}^{0}-E_{1}^{0}\right) z_{1} F / R T .}
$$

Звідси випливає, що поверхневі концентрації двох сортів іонів в умовах концентраційної поляризації при сумісному розряді зв’язані між собою і залежать від заряду іонів та їх стандартного потенціалу.

Якщо після розряду іонів протікає гетерогенна хімічна реакція синтезу, то можна записати умову матеріального балансу

$$
\frac{d C_{1}}{d t}+\frac{d C_{2}}{d t}=\frac{i_{1}}{z_{1} F}+\frac{i_{2}}{z_{2} F}-v
$$

де $v$ - швидкість хімічної реакції; $i_{1}, i_{2}$ - густина струму для іонів першого та другого сорту.

В стаціонарних умовах маємо

$$
\frac{i_{1}}{z_{1} F}+\frac{i_{2}}{z_{2} F}-v=0
$$


Для катодних процесів із сповільненою реакцією синтезу перенапруга пов’язана 3 надлишком речовини $M_{1}, M_{2}$ порівняно з рівноважною концентрацією. При рівноважних концентраціях хімічна реакція знаходиться в рівноважних умовах. Змінами поверхневих концентрацій іонів $M_{1}^{z_{1}}, M_{2}^{z_{2}}$, обумовленими протіканням процесів міграції та дифузії в приелектродному шарі, ми будемо нехтувати, вважаючи, що вони швидкі та встигають підтримувати значення цих концентрацій постійними. Протікання гетерогенної хімічної реакції синтезу обумовлює зміни концентрацій частинок, які визначають потенціал $\mathrm{i}$, як наслідок, призводять до поляризації електрода.

При протіканні процесів, лімітуючою стадією яких є хімічна реакція, рівновага стадії розряд-іонізація практично не порушується, а потенціал електрода визначається рівнянням концентраційної поляризації, обумовленої хімічним масопереносом (рівнянням Нернста) [3]. Концентрація в рівнянні Нернста у розглядуваному випадку змінюється не за рахунок процесів дифузії або міграції, а за рахунок протікання хімічної реакції.

Швидкість процесу синтезу $v$ визначаються рівнянням

$$
v=k_{1} C_{M_{1}} C_{M_{2}}-k_{2} C_{M_{1} M_{2}}
$$

де $k_{1}, k_{2}-$ константи швидкості прямої та зворотної хімічних реакцій; $C_{M_{1} M_{2}}-$ концентрація $M_{1} M_{2}$. Ми будемо нехтувати змінами концентрації $M_{1} M_{2}$ порівняно 3 рівноважною $C_{M_{1} M_{2}}=C_{M_{1} M_{2}}^{0}$. Врахувавши, що в рівноважних умовах маємо $k_{2} C_{M_{1} M_{2}}^{0}=k_{1} C_{M_{1}}^{0} C_{M_{2}}^{0}$, швидкість процесу синтезу можна записати у вигляді

$$
v=k_{1} C_{M_{1}}^{0} C_{M_{2}}^{0}\left(\frac{C_{M_{1}}^{s} C_{M_{2}}^{s}}{C_{M_{1}}^{0} C_{M_{2}}^{0}}-1\right) .
$$

Враховуючи лише вплив подальшої сповільненої гетерогенної хімічної реакції на потенціал електрода, із виразів (4)-(6), (8) та (10) можна визначити рівняння поляризаційної кривої. В результаті математичних перетворень отримаємо кінцевий результат для електрохімічного синтезу

$$
\eta_{1}+\frac{z_{2}}{z_{1}} \eta_{2}=\frac{R T}{z_{1} F} \ln \left[1+\frac{i_{1}(1+\chi)}{i_{01}}\right]
$$

де

$$
\eta_{1}=E-E_{1}^{0}, \quad \eta_{2}=E-E_{2}^{0}, \quad \chi=\frac{z_{1}}{z_{2}} \frac{i_{2}}{i_{1}}, \quad i_{01}=z_{1} F v_{0}, \quad v_{0}=k_{1} C_{1}^{0} C_{2}^{0} .
$$

Із рівняння (11) видно як змінюються перенапруги двох паралельних реакцій, коли є сповільнена хімічна реакція синтезу на поверхні електрода. Рівняння (11) можна записати у вигляді

$$
\eta_{1}=\frac{z_{2}}{z_{1}+z_{2}}\left(E_{2}^{0}-E_{1}^{0}\right)+\frac{R T}{\left(z_{1}+z_{2}\right) F} \ln \left[1+\frac{i_{1}(1+\chi)}{i_{01}}\right],
$$


Puc. 2. Залежності перенапруг $\eta_{1}$ (крива 1) та (крива 2) від значень густини струму для іонів першого та другого сорту $i_{1}$ та $i_{2}$ при $F=96500$ Кл/моль; $R=8,314$ Дж/моль $\cdot \mathrm{K} ; T=1000^{\circ} \mathrm{K}$, $C_{1}^{0}=10^{-3}$ моль $/ \mathrm{cm}^{2}, C_{2}^{0}=10^{-3}$ моль $/ \mathrm{cm}^{2}, k_{1}=100 \mathrm{~cm}^{2} \cdot$ моль $/ \mathrm{c}$, $E_{2}^{0}=E_{1}^{0} \mathrm{MB}, \frac{i_{1}}{i_{2}}=2, z_{1}=1, z_{2}=6$.

$$
\eta_{2}=\frac{z_{1}}{z_{1}+z_{2}}\left(E_{1}^{0}-E_{2}^{0}\right)+\frac{R T}{\left(z_{1}+z_{2}\right) F} \ln \left[1+\frac{i_{2}}{i_{02}}\left(1+\frac{1}{\chi}\right)\right],
$$

де $i_{02}=z_{2} F v_{0}$.

На рис. 2 показано поляризаційні криві при сумісному розряді іонів металів з подальшою сповільненою гетерогенною хімічною реакцією. Зсув перена-

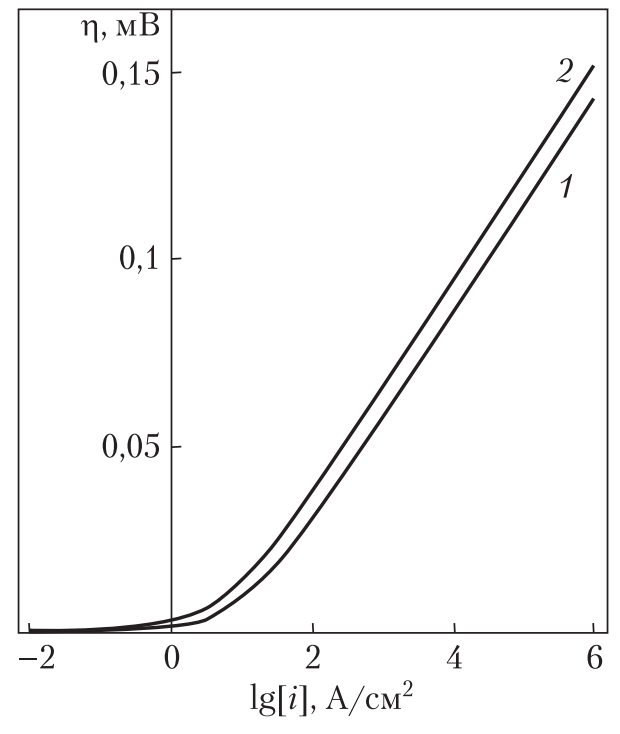
пруги залежить від величини заряду іонів, що розряджаються, густини струмів розряду та густини струму обміну хімічної реакції синтезу, різниці значень стандартних потенціалів.

У загальному випадку рівняння (3) має вигляд

$$
x M_{1}+y M_{2} \rightleftarrows M_{1 x} M_{2 y},
$$

де $x, y$ - стехіометричні коефіцієнти реакції. Швидкість процесу синтезу дорівнює

$$
v=k_{1} C_{M_{1}}^{x} C_{M_{2}}^{y}-k_{2} C_{M_{1 x}} C_{M_{2 y}}
$$

У рівноважних умовах $v=0$. Звідки маємо $k_{1}\left(C_{M_{1}}^{0}\right)^{x}\left(C_{M_{2}}^{0}\right)^{y}=k_{2} C_{M_{1 x} M_{2 y}}^{0}$.

Припустивши, що концентрація $M_{1 x} M_{2 y}$ змінюється несуттєво в порівнянні з рівноважною $C_{M_{1 x} M_{2 y}}=C_{M_{1 x} M_{2 y}}^{0}$, рівняння (15) можна записати наступним чином:

$$
v=v_{0}\left(\left(\frac{C_{M_{1}}}{C_{M_{1}}^{0}}\right)^{x}\left(\frac{C_{M_{2}}}{C_{M_{2}}^{0}}\right)^{y}-1\right)
$$

де $v_{0}=k_{1}\left(C_{M_{1}}^{0}\right)^{x}\left(C_{M_{2}}^{0}\right)^{y}-$ швидкість обміну хімічної реакції синтезу в загальному випадку.

Для стаціонарного процесу

$$
\frac{i_{M_{1}}}{z_{1} F}+\frac{i_{M_{2}}}{z_{2} F}=v_{0}\left(\left(\frac{C_{M_{1}}}{C_{M_{1}}^{0}}\right)^{x}\left(\frac{C_{M_{2}}}{C_{M_{2}}^{0}}\right)^{y}-1\right) .
$$

Враховуючи (4)-(8) та (17), отримаємо вирази для поляризаційних кривих для іонів металу першого та другого сорту в загальному випадку

$$
E-E_{1}^{0}=\frac{z_{2}}{z_{1}+z_{2}}\left(E_{2}^{0}-E_{1}^{0}\right)+\frac{R T}{\left(z_{1} x+z_{2} y\right) F} \ln \left[1+\frac{i_{1}(1+\chi)}{i_{01}}\right],
$$




$$
E-E_{2}^{0}=\frac{z_{1}}{z_{1}+z_{2}}\left(E_{1}^{0}-E_{2}^{0}\right)+\frac{R T}{\left(z_{1} x+z_{2} y\right) F} \ln \left[1+\frac{i_{2}}{i_{02}}\left(1+\frac{1}{\chi}\right)\right] .
$$

Таким чином, при сумісному розряді два незалежних електродних процеси стають залежними один від одного. У випадку концентраційного контролю, коли один з іонів розряджається в умовах граничного струму, електродні процеси є незалежними один від одного.

Змішаний кінетично-концентраційний контроль. Нехай іони першого сорту розряджаються за законом Батлера-Фольмера. Для катодного процесу можна записати

$$
i_{1}=i_{01} \frac{C_{1}^{s}}{C_{1}^{0}} \exp \frac{\alpha z_{1} F}{R T}\left(E-E_{1}^{0}\right)
$$

де $\alpha$ - коефіцієнт переносу заряду; $i_{01}$ - густина струму обміну для першого сорту іона; $F$ - постійна Фарадея; $R$ - газова постійна; $T$ - абсолютна температура.

Для іонів другого сорту виконується рівняння Нернста (5)

$$
E=E_{2}^{0}+\frac{R T}{z_{2} F} \ln \frac{C_{2}^{s}}{C_{2}^{0}} .
$$

Із рівняння (20) маємо

$$
\ln \frac{i_{1}}{i_{01}}=\ln \frac{C_{1}^{s}}{C_{1}^{0}}+\frac{\alpha z_{1} F}{R T}\left(E-E_{1}^{0}\right),
$$

або

$$
E=E_{1}^{0}+\frac{R T}{\alpha z_{1} F} \ln \frac{i_{1}}{i_{10}}-\frac{R T}{\alpha z_{1} F} \ln \frac{C_{1}^{s}}{C_{1}^{0}} .
$$

Після математичних перетворень у випадку, коли розряд одного іона описується рівнянням Батлера-Фольмера, а другий іон розряджається в умовах концентраційної поляризації із рівнянь (23) та (5) маємо

$$
\frac{i_{1}}{i_{01}}=\exp \left[\alpha z_{1} \frac{F}{R T}\left(E_{2}^{0}-E_{1}^{0}\right)\right]\left(\frac{C_{1}^{s}}{C_{1}^{0}}\right)^{-1}\left(\frac{C_{2}^{s}}{C_{2}^{0}}\right)^{\alpha z_{1} / z_{2}} .
$$

Це рівняння показує, що при сумісному розряді величина густини струму першого іона залежить від концентрацій на поверхні та в об'ємі іонів другого сорту та їх стандартного потенціалу.

Кінетичний контроль. Сповільнений розряд обох іонів. Розглянемо випадок, коли розряд обох іонів відбувається за законом Батлера-Фольмера. У випадку кінетичного контролю величина густини струму іонів першого та другого сорту для катодного процесу описується системою рівнянь:

$$
i_{1}=i_{01} \frac{C_{1}^{s}}{C_{1}^{0}} \exp \frac{\alpha_{1} z_{1} F}{R T}\left(E-E_{1}^{0}\right)
$$




$$
i_{2}=i_{02} \frac{C_{2}^{s}}{C_{12}^{0}} \exp \frac{\alpha_{2} z_{2} F}{R T}\left(E-E_{2}^{0}\right) .
$$

Після математичних перетворень маємо

$$
\frac{i_{2}}{i_{20}}=\left(\frac{i_{1}}{i_{10}}\right)^{\alpha_{2} z_{2} / \alpha_{1} z_{1}} \frac{C_{2}^{s}}{C_{2}^{0}}\left(\frac{C_{1}^{s}}{C_{1}^{0}}\right)^{\alpha_{2} z_{2} / \alpha_{1} z_{1}} \exp \frac{\alpha_{2} z_{2} F}{R T}\left(E_{2}^{0}-E_{1}^{0}\right)
$$

Таким чином, при сумісному розряді два незалежних електродних процеси стають залежними один від одного.

\section{ЦИТОВАНА ЛІТЕРАТУРА}

1. Хейфец В.Л., Ротинян А.Л. Закономерности совместного разряда ионов и теория электролитического рафинирования металлов. ДАН СССР. 1952. 82. С. 423-426.

2. Vagramyan A.T., Fatueva T.A. On the theory of simultaneous discharge of metal ions in real conjugagated systems.J. Electrochem. Soc. 1963. 110. P. 1030-1035.

3. Дамаскин Б.Б., Петрий О.А. Введение в электрохимическую кинетику. Москва: Высшая школа, 1983. C. $298-303$.

4. Барабошкин А.Н. Электрокристаллизация металлов из расплавленных солей. Москва: Наука, 1976. C. $221-226$.

5. Шаповал В.И, Малышев В.В., Новоселова И.А., Кушхов Х.Б. Современные проблемы высокотемпературного электрохимического синтеза соединений переходных металлов IY-ҮІ групп. Успехи химии. 1995. 4. С. $35-38$.

6. Шаповал В.И., Волков С.В., Потоцкая В.В. К теории электрохимического синтеза. Допов. Наи. акад. наук Укр. 2001. № 2. С.152-157.

7. Karimzadeh A., Aliofkhazraei M., Walsh F.C. A review of electrodeposited Ni-Co alloy and composite coatings: microstructure, properties and applications. Surface $\mathcal{E}$ Coatings Technology. 2019. 372. P. 463-498. https:// doi.org/10.1016/j.surfcoat.2019.04.079.

Надійшло до редакції 24.03.2021

\section{REFERENCES}

1. Heifetz, V. L. \& Rotinyan, A. L. (1952). Mechanisms of simultaneous discharge of ions and theory of electrolytic refining of metals. DAN SSSR, 82, No. 2, pp. 423-426 (in Russian).

2. Vagramyan, A. T. \& Fatueva, T. A. (1963). On the theory of simultaneous discharge of metal ions in real conjugagated systems. J. Electrochem. Soc., 110, No. 10, pp. 1030-1035.

3. Damaskin, B. B. \& Petrii, O. A. (1983). Introduction into electrochemical kinetics. Moscow: Vysshaya. Shkola, pp. 298-303 (in Russian).

4. Barabashkin, A. N. (1976). Electrocrystallization of metals from molten salts. Moscow: Nauka, pp. 221-226 (in Russian).

5. Shapoval, V. I., Malyshev, V. V., Novoselova, I. A. \& Kushkhov, Kh. B. (1995). Modern problems of high-temperature electrochemical synthesis of compounds of transition metals of IY-YI groups. Uspekhi khimii, 4, pp. 35-38 (in Russian).

6. Shapoval, V. I., Volkov, S. V. \& Pototskaya, V. V. (2001). On theory of electrochemical synthesis. Dopov. Nac. akad. nauk Ukr., 2, pp. 152-157 (in Russian).

7. Karimzadeh, A., Aliofkhazraei, M. \& Walsh, F. C. (2019). A review of electrodeposited Ni-Co alloy and composite coatings: microstructure, properties and applications. Surface \& Coatings Technology, 372, pp. 463-498. https://doi.org/10.1016/j.surfcoat.2019.04.079.

Received 24.03.2021 
V. V. Pototskaya ${ }^{1}$, https://orcid.org/0000-0001-7269-9592

O. I. Gichan ${ }^{2}$, https://orcid.org/0000-0002-5812-9451

A. O. Omelchuk ${ }^{1}$, https://orcid.org/0000-0002-8799-2115

${ }^{1}$ Vernadskii Institute of General \& Inorganic Chemistry of the NAS of Ukraine, Kyiv

${ }^{2}$ Chuiko Institute of Surface Chemistry of the NAS of Ukraine, Kyiv

E-mail: omelchuk@ionc.kiev.ua, gichan@meta.ua

\section{REGULARITIES OF THE SIMULTANEOUS DISCHARGE OF IONS. THEORY OF ELECTROCHEMICAL SYNTHESIS}

The mechanisms of simultaneous discharge of two ions for different conditions of electrode polarization [concentration polarization, mixed (concentration-kinetics) polarization, and kinetic control in the case of delayed discharge of both ions] are shown. We show how the independent processes of discharge of ions become dependent at the simultaneous discharge. The equation of polarization curve for the electrochemical synthesis in the case of concentration polarization of the electrode is derived (we consider the simultaneous discharge of two ions and the proceeding delayed heterogeneous chemical reaction of synthesis). The overvoltage shift depends on the charge of ions discharged, density of discharge currents, density of exchange current of the chemical reaction of synthesis, and difference in the standard potentials.

Keywords: simultaneous discharge, polarization curve, electrochemical synthesis, alloys. 